\title{
China's Sea Floor Observatory Network R\&D: Current Status and Prospects
}

\author{
Xin $\mathrm{Li}^{* 1}$, Bin Fu ${ }^{* 2}$, Song $\mathrm{Hu}^{* 1}$, Jiemin $\mathrm{Lin}^{* 1}$ \\ ${ }^{* 1}$ College of Economics and Management, Shanghai Ocean University \\ ${ }^{*} 2$ The State Key Laboratory of Ocean Engineering, Shanghai Jiao Tong University \\ (Email:xinli@shou.edu.cn)
}

\begin{abstract}
As many countries in the world pay great attention to marine science research and development, Sea Floor Observatory Network (SFON) technology has been more and more important. In this article, the definition and history of SFON are briefly introduced, the development and current status of SFON of various countries are compared, and key technologies for SFON are analyzed. In the end, the prospects of China's SFON are discussed and advices are given.
\end{abstract}

Key words: Sea Floor Observatory Network (SFON); Current Status; Key Technology; China

\section{Introduction}

The ocean, which has not been completely exploited by human, has been regarded as an important strategic area by many countries in recent years, as the population, resource and environment problems become more and more serious. Thus, there is a growing demand for the technology related to understanding and using the ocean. A revolution in ocean observing is developing that will greatly change our view of the ocean. The objective is to make long-term real-time 3-dimensional monitoring of the ocean via a Sea Floor Observatory Network (SFON). SFON is the third important platform after surface observations and satellites ${ }^{[1]}$, and it will change the way of studying the ocean and found a new era of oceanography.

SFON is consisted of on-land stations and underwater observatory nodes, which are connected via high-speed cable to transmit real-time data for physical, chemical and biological processes in the ocean. These data can be used for protecting environment, developing resource, preventing disaster and improving homeland security. Major developed countries have started the SFON projects. In the past 20 years, the investments on SFON have been growing rapidly, such as Canada NEPTUNE project (Fig. 1), U.S. OOI project, Europe ESONET and Japan ARENA project. Now, the U.S., Europe and other developed countries have completed the construction of SFON.

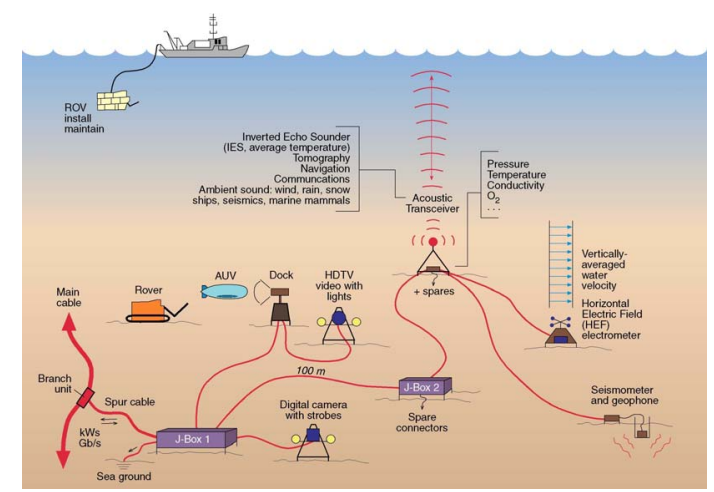

Fig.1 Sketch of deployment of NEPTUNE node

China, with broad blue national territory, is just beginning to develop the technology on SFON. It is rather an opportunity than a historical mission. The construction of SFON in China and scientific research on related high-tech will not only bring China the breakthrough in science, but also benefit the development of the marine economics.

2. The international race for seafloor observatory network

Starting from the 90s, western countries such as U.S., England, Italy and Asian countries such as Japan and South Korea have developed many deep-sea monitoring technology and devices, and established long-term deep-sea observatory stations and network based on large amount of investments. The earliest offshore sea floor observatory station is now been updated to offshore sea floor observatory network. The network based on power cable and optic 
cable is now updated to the network including satellite data. Part of the SFON now can transmit data via satellites. Although each country pays great attention on this field, the developments of SFON in these countries are very different, partly because SFON technology is still in the phase of research and development.

\subsection{U.S.}

In this fermentative marine competition, the U.S. is walking on the forefront.

2.1.1 Moves: The SFON which the U.S. has already completed are the long-term ecosystem observational network (Long-term Ecosystem Observatory at 15 meters,LEO-15,1996 ) , Hawaii Underwater Geo-Observatory (HU GO, 1997) , Hawaii-2 Observatory $(\mathrm{H} 2 \mathrm{O}, 1998)$ as well as Mart-has Vineyard Coastal Observatory (MVCO) ${ }^{[2]}$.

2.1.2 Current Status: After more than ten years discussion, the U.S. passed the plan of interactive Ocean Observatory Initiative (OOI), which is composed by the offshore, the regional, and the global seafloor observatory systems at the end of June 2006. This plan was started in 2009 due to the lack of fund support (originally planned to start in 2007). The system was planned to operate for 30 years, among which the most important component is a regional seafloor observatory network, namely Northeast Pacific Ocean's Neptune (NEPTUNE) plan.

2.1.3 Organization: the U.S. National Science Foundation (NSF) established the Ocean Research Interactive Observatory Network (ORION) organization to operate and manage observatory stations.

\subsection{Japan}

The development of Japanese seafloor observatory network is characterized by 1 ) early plan, 2) great investment, 3) rapid development, and 4) highly interactive.

2.2.1 Moves: In 1978, Japan constructed in the region of Omaezaki the first seafloor real-time observatory system constituted by the coaxial submarine cable to real-time monitor the earthquake and few concomitance tsunami, and constructed the second submarine cable observatory system ${ }^{[3]}$ in 1985 in the region of Boso.

2.2.2 Current Status: So far, Japan has in total 8 submarine cable observatory systems to monitor the earthquake and the tsunami. The seafloor optical fiber cable observatory system of Omaezaki region, the regional high-quality real-time Earth Monitoring network (A-RENA) and the observatory network system (DONET) are under construction or in plan.

2.2.3 Organization: JAMSTEC, the Japanese Department of Meteorology, the Japan University of Tokyo's Earthquake Research Institute, the Geoscience and the Disaster Prevention National Research Institute, University of Tokyo and other institutes participate in the development of seafloor observatory network construction.

\subsection{Canada}

2.3.1 Moves: "NEPTUNE Canada" is the largest seafloor observatory network system in the world till now. It was officially started in December 2009.

2.3.2 Current Status: Beside NEPTUNE, a project called Victoria Experiment Network Under the Sea (VENUS) is carrying on.

\subsubsection{Organization: Victoria University.}

\subsection{Europe}

2.4.1 Moves: EC has supported a series of seafloor observatory system from 1995 to 2005;

2.4.2 Current Status: NESTOR, which is used in submarine miniature neutron research, the European first real-time submarine cable observatory system - Neutrino Mediterranean Observatory Submarine Network-1 (NEMO-SN-1), Mars observational network (AN TARES) and the Gas Monitoring Module (GMM) were already completed. The Cubic kilometer Deep Sea Neutrino Telescope $(\mathrm{KM} 3 \mathrm{NeT})$, ESONET and the European Multidisciplinary Seafloor Observatory (EMSO) and others are under construction.

The current statuses of various countries' SFON are listed in Table 1. Further analyses are given following for four aspects:

Function The U.S. and Canada's SFON serve both scientific study and economic development. Japan mainly focuses on monitoring the earthquake and tsunami.

Organization Most organizations are research institutes, universities and government organizations. Few enterprises are found to participate.

Time Although most countries started their moves from the $90 \mathrm{~s}$, the constructions of SFON become intensive especially in recent years, probably because of the increasing occurrence of the extreme weather and 
natural disaster.

Investment The investment is increasing. NEPTUNE Canada planned to invest more than 100 million US dollar. Japan has constructed the biggest scientific drilling ship around the world which called "the Earth" costing about 500 600 million US dollars.

Table.1 The comparison of current status of major regions' SFON

\begin{tabular}{|c|c|c|c|c|}
\hline Region & Count & Representative & Organizations & Drivers \\
\hline U.S. & 4 & OOI & $\begin{array}{l}\text { US National Science Foundation, } \\
\text { Montrie marine life research institute, } \\
\text { Reuters garth university and WETSA T } \\
\text { Corporation, Washington University, } \\
\text { University of California, Woods hole } \\
\text { research center and so on }\end{array}$ & $\begin{array}{l}\text { Monitoring the Juaneph card } \\
\text { tectonic plate, observing the } \\
\text { Arctic Regions }\end{array}$ \\
\hline Europe & 7 & ESONET & 14 Europe continent research institutes & $\begin{array}{l}\text { Monitoring environment and } \\
\text { security around the world }\end{array}$ \\
\hline Japan & 8 & ARENA & $\begin{array}{l}\text { JAMSTEC, the Japanese Department of } \\
\text { Meteorology, the Japan University of } \\
\text { Tokyo earthquake research institute and } \\
\text { Japan University of Tokyo and so on }\end{array}$ & $\begin{array}{l}\text { Monitoring of the earthquake } \\
\text { and tsunami }\end{array}$ \\
\hline Canada & 2 & NEPTUNE & Victoria University & $\begin{array}{l}\text { Revelation of the continental } \\
\text { shelf's carbon cycle pattern }\end{array}$ \\
\hline China & 1 & $\begin{array}{c}\text { East China Sea } \\
\text { seafloor } \\
\text { observatory } \\
\text { network }\end{array}$ & $\begin{array}{l}\text { The research team led by academician } \\
\text { Wang Pinxian (the Tongji University, the } \\
\text { Zhejiang University, Shanghai Jiao Tong } \\
\text { University, China Ocean University, sea } \\
\text { bureau East China Sea Sub-bureau } \\
\text { unites research) }\end{array}$ & $\begin{array}{l}\text { The Essential factor of sea } \\
\text { synthesis observations such as } \\
\text { earthquake, tsunami, } \\
\text { hydrology, meteorology, } \\
\text { geology, silt, chemistry and so } \\
\text { on }\end{array}$ \\
\hline
\end{tabular}

Based on the experience of developed countries, SFON may be regarded as the new platform which integrates information technology, communication technology, computer technology and the electric cable or the optical fiber infrastructure hardware (Fig.2). Because ROV, seafloor observatory and conjunction box are the necessary devices of SFON, it is a must to solve these key technologies to construct a SFON.

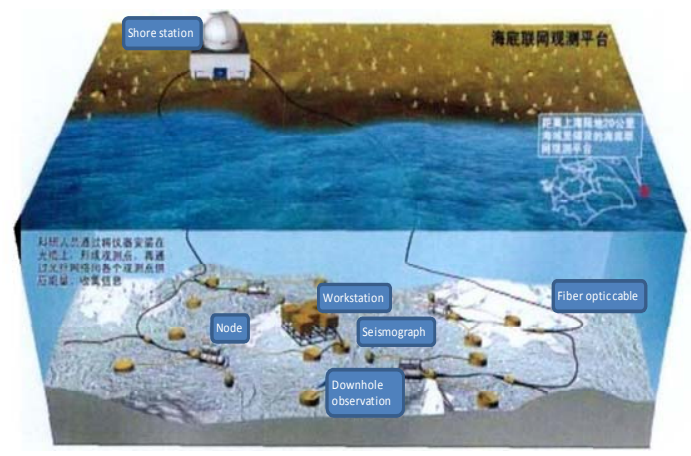

Fig.2 Location of Monterey Accelerated Research System ${ }^{[4]}$

\section{Current Status and Crucial Technical Problems of China's SFON}

\subsection{Current Status of China's SFON}

Although Chinese research vessels were quite active in the past ten years, China still falls far behind other Asian countries in the aspect of ocean observation, especial long-term observation; at the same time, the China's economic development faces the resource, efficiency and environment problems, which become increasingly prominent. Thus, it is necessary to construct SFON to increase the ability of long-term real-time monitoring of the ocean, which is significant for protecting the ecosystem and fisheries. Meanwhile, the construction of SFON can promote the local economics and provide jobs for the society. Now, China experiences the very good opportunity in history with the rapid growth of scientific investment; it is worth thinking deeply by Chinese scientific community to catch this opportunity and put efforts on the right place. In view of this, Pinxian Wang and many other scientists initiated research on the SFON, proposing a tentative plan that "watches" the ocean from the sea floor upward to the sea surface. The plan got high attention of 
national government. The government initially established the Chinese first sea floor submarine integrated observatory experiment and demonstration system - - the East China Sea seafloor observatory station in Xiaoqushang and enhanced the ability of forecasting the marine disaster and handling the emergency. Although it is relatively late for China to develop the systematic research on SFON, but it has formed a pattern which is headed by the government, led by the research institution and cooperated by enterprises (Table 2). They together impel SFON to develop forward. At present, the Chinese SFON can be divided into the following three stages:

The first stage is the validation of key technology. "Key technologies of seafloor long-term observatory network experiment nodes" is a key project in "eleventh five-year plan". The project's goal is to study and develop the conjunction box and the communication technology, the seafloor power environment and chemistry monitor technology, the standard of deep-sea network and the system integration and other key technologies. A series of experiments were conducted with the cooperation of MARS network and real-time data were obtained using the international observatory network (Fig. 3).

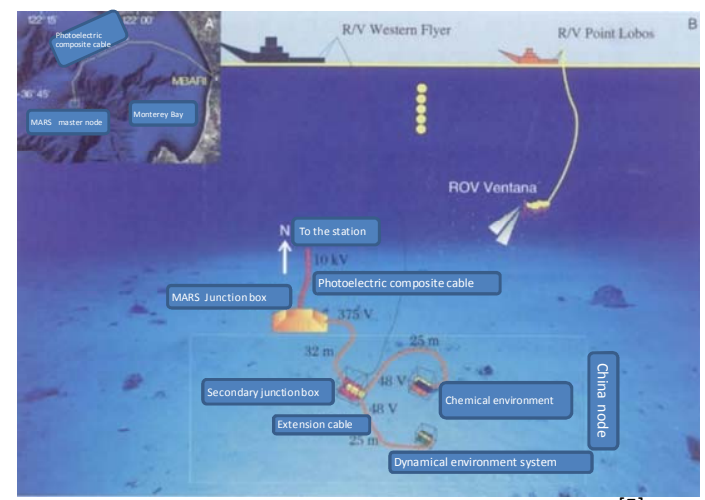

Fig.3 Sketch of deployment of China node ${ }^{[5]}$

The second stage aims to establish a network in a small region around Changjiang delta and put into operation. In 2009, the first underwater ocean observatory experiment and demonstration, Xiaoqushan station in East China Sea, was established, led by Tongji University (Fig. ${ }^{[6]}$ ). The cable is one kilometer long. It transmits water temperature, salinity and pressure information every 15 seconds.
On 27th Feb 2010, an earthquake of measuring 8.8 stroke central parts of Chill. Xiaoqushan station successfully captured the sea level anomaly after the earthquake. Based on the monitoring data, China's researchers plan to validate and improve the tsunami forecast model ${ }^{[7]}$.

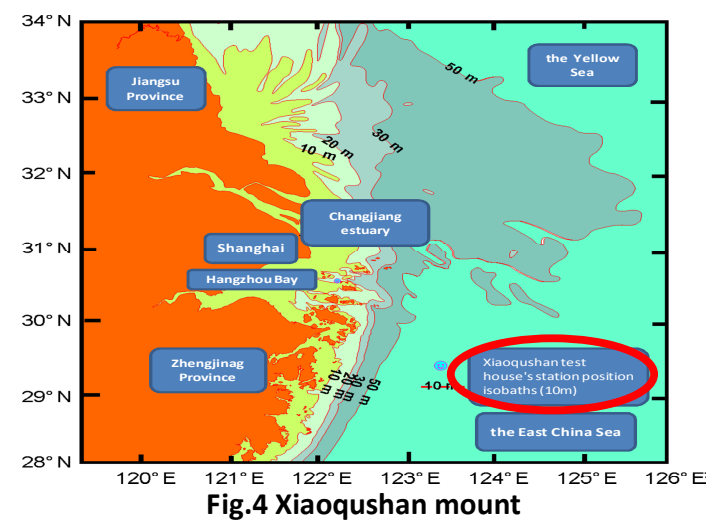

The third stage aims to construct large-scale SFON. The East China Sea SFON Project is initiated by a fund of 40 million Yuan from Shanghai government and is expected to complete in five years. The central government sets up a budget of more than one billion Yuan to build network in East China Sea and South China Sea, which is a large-scale nervous system of sea floor observation (Fig. 5).

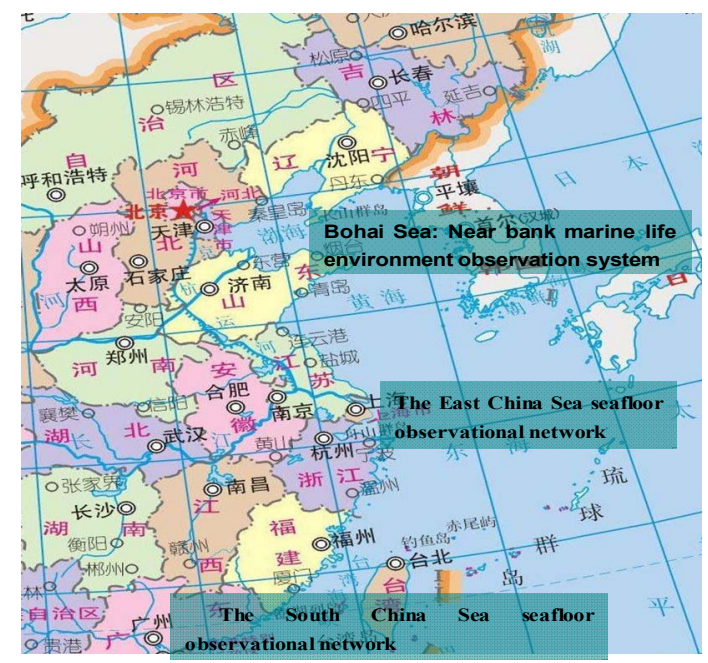

Fig.5 Geographic distribution of Ocean observatory

China's SFON is constructed under the full government financial support and by efficient groups consisted of many research institutes and companies. The international successful experience also provides a solid basis for the development of China's SFON 
technology. At the same time, the construction of the network will bring great benefits for both economics and society and promote the sustainable development of economics. For example, in China's most developed area, Changjiang delta, the improvement of the network technology will enhance the competition ability, which directly benefits the local ocean engineering industry and promote the local economics. On the other side, the ocean engineering industry may cause side effects, such as sediment deposition on waterway and engineering, and large-scale biological extinction caused by eutrophication. The network can provide precaution information of ecosystem, protect the environment and fisheries security, and help determine the marine policy for emergency.

Table 2 The development of China's SFON

\begin{tabular}{l|l}
\hline \multirow{2}{*}{2005} & $\begin{array}{l}\text { National Guideline on Medium- and Long-Term Program for Science and Technology } \\
\text { Development }\end{array}$ \\
\cline { 2 - 2 } 2007 & "The suggestion of constructing SFON \\
\hline \multirow{2}{*}{2009} & $\begin{array}{l}\text { Chinese first Sea Floor Submarine Integrated Observation Experiment and Demonstration } \\
\text { System }\end{array}$ \\
\hline \multirow{2}{*}{2010} & Sea surface anomaly captured by Xiaoqushan station after Chili's 8.8 level earthquake \\
\cline { 2 - 2 } & "Build devices for sea floor observatory network system" proposed \\
\cline { 2 - 2 } & $\begin{array}{l}\text { Center for marine science and technology established by Tongji University, Jiaotong } \\
\text { University, East China Normal University and other institutes. }\end{array}$ \\
\cline { 2 - 2 } 2011 & Experiments were conducted offshore and successful \\
\hline \multirow{2}{*}{20 "The East China Sea Floor observatory network" initiated } \\
\hline
\end{tabular}

\subsection{Crucial technical problems}

After more than ten years' endeavor, China's marine technology had the unprecedented progress, grasping a batch of key technologies. However, compared with developed countries, China's ability of development still falls behind the international advanced level at present, in particular for the deep-sea technology and the equipment. Many core devices and the technologies still rely on the import; there are the technical blockade and the trade barrier, which has limited China's development in the ocean. At present, China's SFON is still in the phase of beginning and many key technologies are still in the experiments. Although buoys were employed offshore and an ecosystem and environmental monitoring system was built in Bohai Sea, the SFON including many nodes are not constructed yet. Institutes in China have developed a batch of sensors and instruments. However, compared with the international level, China still has certain disparity in the sea observation network construction technology, the application technology and the management machine-made aspect at present. An operational SFON is not built yet.

The main technical problems can be summarized as following: the deep sea electrical energy converter's stability and reliability are inferior to the international advanced level; the cable high voltage isolation technology needs further improved; the base depot construction technology needs further improved; the submarine multiple joint technology needs further development; the high and low pressure electrical energy converter radiation needs further solution; the monitor sensor which can sense the actual usage of the energy is few; the intellectualized seafloor monitor equipment which based on networking needs further study; the equipment of the seafloor monitors' long-term stability needs further testing; the experience of using network special-purpose ROV and the corresponding arrangement is lack.

\section{Prospects of China's SFON}

The development of SFON is not only related to technology; it is to reform the whole structure of observation system, involving the changes of many aspects such as 
scientific vision, research methods, national strategy, marine policy and investment decision.

\subsection{Increase the investment and carry on the effective management by supervision}

China's SFON industry, at its early stage, needs the systematic and necessary policy support, especially the investment for the related significant science and technology projects. The procedures of Canadian and Japanese Government that provided large amount of fund to establish the seafloor observatory network research and development are good examples. Even after the establishment of SFON, one natural difficulty of SFON is the long-term maintenance problem which costs a lot. Moreover, the country must carry on supervising and managing on the investment, pay great attention to the efficiency and consider the national and regional economical conditions. Therefore, it is necessary to strengthen the investment management and accurately analyze the benefits and costs.

\subsection{Increase efficiency and international cooperation}

In China, the organizations related with ocean development include national institutes and many other smaller organizations. Many organizations often are supported by different science plan or project alone, resulting in resource dispersion, redundant research, repetition investment, and difficulty for "data sharing". Therefore, the national administration should initiate and establish the development of the seafloor observatory network which can concentrate the investment and research resources, form high-level research teams and avoid repetition wastes. Although various countries' development priorities and the road map somewhat are possibly different, but the needs of the technologies are same. For this reason, the administration should track the international seafloor observatory network's development closely, impel the related international cooperation positively, improve the key component related new technology, and share the seafloor observed data.

\subsection{Huge economic benefit brought by SFON}

The innovation technology plays a key role in transforming the economic structure. By conducting SFON, the technologies related to communication system, data management and software application will promote local economics. On the other side, once the accurate forecasts of atmospheric and oceanic processes are used by producers and consumers to help their economic-related activities and decisions, huge economic benefit will be produced ${ }^{[8]}$.

\subsection{Spread the knowledge of SFON}

For the past few decades, China's economics grow rapidly and the commercial activities of China have already spread all over the global ocean. However, the popular science education of the ocean spirit or ocean consciousness has not followed. The national administration should spread the knowledge of SFON to the general public. By doing this, it will lay the foundation for the promotion of future SFON construction.

\section{References}

[1] Pinxian Wang. Seaflooor Observatories: The Third Platform for Earth System Observation[J]. Chinese Journalof Nature ,2007(29): 125-131.

[2] FAVAL I P,BERANZOL I L.Seafloor observatories, benefit $s$ for the marine and earth sciences : International and European perspectives towards networks [EB/ OL ] . [ 2008-07-05 ] . https :/ / upcommons. upc. edu/ revistes/ bit st ream/ 2099/ 4304/ 1/ pag5_7. pdf.

[3] NEC. Plate boundaries and cable connected ocean bottom observatories around Japan [ EB/ OL ] .[2008-07-29 ] . www. nec. co. jp/ csr/ en/ report/ pdf/ CSR-03. pdf . [4] Shanghai will construct the East China Sea seabed observational network[J]. news brief of disaster reduction, 2011 (2) :88-88.

[5] Peng Xiaotong, Zhou Huaiyang and so on. Test China Node on Monterey Accelerated Research System (MARS) [J] . ADVANCES IN EARTH SCIENCE, 2011 (26):991-996.

[6] Zhang Y W, Fan D D, Xu H P. Records of the tsunami induced by the 2010 Chilean earthquake from Xiaoqushan seafloor observatory in the EastChina Sea[J] . Chinese Sci Bull, 2011(56): 2957-2965.

[7] Yan Du, Yiquan Qi, Ju Chen and so on. East China Sea fixed point continual observation station and ocean current material analysis [J ] oceaneering, 2003 (21) $95-100$. 